\title{
Brain MRI Abnormalities in Children with Wilson's Disease: Is it Indicator for Liver Transplantation?
}

\author{
HOSAM-ELDIN M. BASIOUNY, M.D.*; HANAA A. EL-ARABY, M.D.*; HAZEM OMER, M.D.** and \\ EMAN Z. SEDEEK, M.D.*** \\ The Departments of Pediatric Hepatology, Gastroenterology \& Nutrition* and Interventional Radiology**, \\ National Liver Institute, Menoufia University Shebin El-Koom, Menoufia and \\ The Department of Pediatrics \& Neonatology, El-Mahalla General Hospital, Ministry of Health***, Egypt
}

\begin{abstract}
Background: Wilson's Disease (WD) is an autosomal recessive disorder of copper metabolism with a prevalence of about 1 in 30000 people.It's more common with parental consanguinity. The adenosine triphosphate 7B (ATP7B) gene, coding the copper transporting P-type ATPase has been reported to have 380 variants. Copper leads to tissue damage by accumulating in many organs includingmainly the liver and brain. Neurological manifestations of WD are ascribed toabnormal deposition of copper in brain tissues, especially deep gray matter (basal ganglia and thalamus) and subcortical white matter. Wilson's disease can present clinically by liver disease, neurological disorderor psychiatric illness. In childhood, hepatic manifestations predominate with ahighly variable spectrum ranging from self-limiting hepatitis to fulminanthepatic failure.
\end{abstract}

Aim of Study: The aim of this study was to detect brain changes by magnetic resonance imaging in children with Wilson's disease and their correlation with clinical and biochemical findings.

Patients and Methods: This study included 70 patients. 35 patients with WD and 35 patients with other Chronic Liver Disease (CLD) as control. WD group involved 20 males and 15 females. Their mean age was $(12.73 \pm 2.86)$ year. Control group included 35 patients with CLD (20 with Autoimmune Hepatitis (AIH), two with sclerosing cholangitis and 13 with chronic HCV.

Results: Among WD group, we reported 15 patients $(42.8 \%)$ had abnormal MRI. T1 weighted images showed bilateral symmetrical hyperintensity signal of globuspallidus in two patients $(5.7 \%)$, hypointensity signal of left globuspallidus in one patient $(2.8 \%)$ and bilateral symmetrical hyperintensity in thalami in one patient $(2.8 \%)$. T2 and FLAIR hyperintensity signals mainly involving basal ganglia were present in 11 patients $(31.4 \%)$. Ventricular system was affected in two patients $(5.7 \%)$, it was prominent in one patient and the other patient had hydrocephalus. Patients were followedup over a period of 6-18 months and we reported that three WD patients (20\%) from those who had abnormal MRI dete-

Correspondence to: Dr. Hosam-Eldin M. Basiouny, E-Mail: Hosambasiouny@yahoo.com riorated rapidly and were candidates for LT, while none of other patients needed LT.

Conclusions: Bilateral symmetrical hyperintense signals in T2 weighted and FLAIR images mainly involving basal ganglia are specific for WD and represent CNS involvement of WD. Abnormal MRI may be a bad prognostic factor as $20 \%$ from abnormal MRI WD subgroup deteriorated rapidly and were candidates for LT.

Key Words: Wilson's disease - Chronic liver disease Autoimmune hepatitis - Alanine transaminase - Aspartate transaminase - MRI - LT - HCV.

\section{Introduction}

WILSON'S Disease (WD) is an autosomal recessive disorder of copper transport characterized by reduced copper incorporation into ceruloplasmin and by impaired biliary excretion of copper. This results in progressive copper accumulation in the liver and subsequently in the brain, cornea and other tissues with resultant damage [1]. The pivotal point to achieve the best outcome relies on a timely and accurate diagnosis. This is associated with healthy life-span in patients who are adherent to an effective medical regimen [2]. Scoring system entails a diagnostic approach, in which a variety of clinical and biochemical tests are included. Commonly used biochemical tests are serum ceruloplasmin concentration, 24-hour urinary copper

\footnotetext{
Abbreviations:

WD : Wilson's Disease.

CLD : Chronic Liver Disease.

AIH : Autoimmune Hepatitis.

ALT : Alanine Transaminase.

AST : Aspartate Transaminase.

MRI : Magnetic Resonant Imaging.

PT : Prothrombin Time.

LT : Liver Transplantation.

KF : Kayser Fleischer ring.
} 
excretion and hepatic copper quantitation [3] Neurologic symptoms of WD typically occur between the ages 20-40 years, however the range is very large. The youngest WD patient with neurologic symptoms was aged 6 and the oldest 72 years. The most common neurologic symptoms of WD are movement disorders including tremor, dystonia, parkinsonism and ataxia, which are frequently associated with dysphagia, dysarthria and drooling [4] . Current treatment options for WD, based on drugs leading to negative copper body balance like chelators or Zinc salts, were introduced more than 40 years ago and are generally effective in the majority of WD cases if used lifelong. However, especially in neurological patients, treatment may lead to neurological deterioration, which is often irreversible. Further, almost $50 \%$ of neurologically affected WD patients present with persistent neurological deficits despite the use of anti-copper treatment [5]

Magnetic resonance imaging is a sensitive method to evaluate the brains of patients with WD. Copper, unlike iron, manganese, or calcium is not directly visualized by any of the current imaging technologies but MRI of the brain shows tissue injury, edema, gliosis, or cavitation caused by excessive copper deposition [6] . Neurologic involvement of WD can progress rapidly to a severe debilitating condition [7]. However, there is still paucity of data about brain changes in WD in pediatric age.

\section{Patients and Methods}

This study included 70 patients recruited from Pediatric Hepatolology, Gastroenterology and $\mathrm{Nu}-$ trition Department, National Liver Institute, Menoufia University from Jan. 2017 - Dec. 2020, 35 patients with WD and 35 patients with other CLD as control. Then WD group was subdivided in two groups: Normal MRI group and abnormal MRI group. WD group involved 20 males and $15 \mathrm{fe}$ males. Their mean age was $(12.73 \pm 2.86)$ years. Control group included 35 patients with other CLD (20 with Autoimmune Hepatitis (AIH), two with sclerosing cholangitis and 13 with chronic HCV. They were 16 males and 19 females. Their mean age was (12.74 \pm 3.12$)$ years.

\section{Inclusion criteria for WD patients:}

Initial diagnosis of WD was made if the patient had hepatic and/or neurologic disease in addition to at least two of the following six criteria:

1- Positive family history of WD.

2- Low ceruloplasmin level (<20mg\%).
3- Presence of Kayer Filusher (KF) ring.

4- Liver biopsy suggestive of WD (positive staining of copper associated protein (rhodanine or orcein stain), presence of glycogenated nuclei, microor macrovesicularsteatosis, or ultra-structural changes defined by electron microscopy) as measurement of hepatic copper content is not available in Egypt.

5- Elevated baseline 24-hours urinary copper excretion (more than 100 /2/ hours or more than 1600 o/2 hours after D-Penicillamine challenge test).

6- Coomb's negative hemolytic anemia [8].

All patients were subjected to the following: Full history taking, thorough clinical examination and the following investigations: Liver function tests, PT \& INR, kidney function tests, complete blood count, serum ceruloplasmin, 24 hours urinary copper, abdominal US, liver biopsy (when possible) and brain MRI. Data at time of diagnosis of previously diagnosed cases were collected from patients' files. At time of MRI, liver function tests and 24 hours urinary copper were repeated.

Magnetic resonance images were obtained on a GE Optima MRI scanner with a super-conducting magnet of 1.5T field strength after receiving informed consent from subjects. Spin Echo (SE) T1 weighted (TR $210 \mathrm{~ms}$, TE 13ms) images in axial planes were taken, with an acquisition time of 46.8 second, matrix of $256 \times 256$ pixels and a $230 \mathrm{~mm}$ field of view. Axial and coronal images of T2 weighted images were acquired (TR 3300ms, TE 99ms). FLAIR sequences were obtained in the axial plane (TR $9000 \mathrm{~ms}$, TE $119 \mathrm{~ms}$ ). The slice thickness was $5 \mathrm{~mm}$. MRI observations were interpreted by an expert radiology consultant.

A signed informed consent was obtained from the parents of all patients before enrollment in this study. The study was approved by the Research Ethics Committee of National Liver Institute.

\section{Statistical methods:}

Data were analyzed using the SPSS (Statistical Package for Social Science) program version 21, SPSS Inc., Chicago, Illinois, USA. Qualitative data were expressed as frequency and percentage. Quantitative data were shown as mean \pm Standard Deviation (SD).

\section{Results}

In WD groupthe age of presentation was $(10.03 \pm$ 3.02 ) years. Also in the same group, $51.4 \%$ were 
presented by picture of CLD, $22.8 \%$ presented by acute hepatitis and $3 \%$ with neurologic presentation, while $22.8 \%$ were diagnosed during family screening of siblings of patients(presymptomatic). Dysarthria and abnormal gait were the most common neurological symptoms in WD patients.

When we compared disease severity at time of MRI between WD group and CLD group using Child Pugh score, there was no significant statistical difference between the two groups $(p>0.05)$. We reported that MRI abnormality was significantly statistically higher in WD group than CLD group $(p=0.003)$.

Within CLD group, $8.5 \%$ of patients had abnormal MRI. MRI abnormality was in the form of T 1 hyperintensity in the globuspallidus and anterior midbrain.

Among WD group, we reported 15 patients (42.8\%) had abnormal MRI. T1 weighted images showed bilateral symmetrical hyperintensity signal of globuspallidus in two patients (5.7\%), hypointensity signal of left globuspallidus in one patient $(2.8 \%)$ and bilateral symmetrical hyperintensity in thalami in one patient (2.8\%). T2 and FLAIR hyperintensity signals mainly involving basal ganglia were present in 11 patients $(31.4 \%)$. Ventricular system was affected in two patients $(5.7 \%)$, it was prominent in one patient and the other patient had hydrocephalus.

We reported that globuspallidus was the most common affected site in T1 weighted images in WD group. T2 bilateral basal ganglionic lesions were the commonest changes. Among basal ganglia nuclei, caudate nucleus was the most affected in $\mathrm{T} 2$ weighted images followed by lentiform nucleus then putamen. Lesions in FLAIR images were similar to T2 weighted images. We reported periaqueductal hyperintensity in T2 \& FLAIR images in only one case $(6.6 \%)$.

We reported that MRI brain lesions were bilateral and symmetrical in all patients except in one patient who had signal abnormality affecting only left globuspallidus. Bilateral symmetrical hyperintensity of caudate nucleus in T2 weighted \& FLAIR images was the commonest lesion in patients who had dysarthria and abnormal gait. Brain MRI of the patient who had dystonia showed bilateral symmetrical hyperintensity of caudate nucleus and putamen in T2 \& FLAIR.

It is still not clear when brain involvement in WD becomes symptomatic. We reported that $60 \%$ of WD patients, who had abnormal MRI, were neurologically free at time of MRI. Searching for risk factors of brain involvement in children with WD, we compared between normal MRI and abnormal MRI WD subgroups as regard type of presentation, liver function tests, 24 hours urinary copper at time of MRI, duration of illness and Child Pugh score at time of MRI and we found that, there was no significant statistical difference between the two groups as regard liver function $(p<0.05)$ except AST/ALT ratio which was significantly statistically higher in abnormal MRI WD subgroup than normal MRI subgroup $(p<0.05)$.

We reported that all presymptomatic patients had normal MRI. Patients were followed-up over a period of six months to one year and half and we reported that three WD patients (20\%) from those who had abnormal MRI deteriorated rapidly and were candidates for LT, while none of other patients needed LT.

Table (1): Comparison between WD group and CLD group as regard $\mathrm{T} 1$ weighted images findings.

\begin{tabular}{|c|c|c|c|}
\hline $\mathrm{T} 1$ & $\begin{array}{c}\text { WD } \\
\mathrm{n}=35 \mathrm{n}(\%)\end{array}$ & $\begin{array}{c}\text { CLD } \\
\mathrm{n}=35 \mathrm{n}(\%)\end{array}$ & $\begin{array}{c}p- \\
\text { value }\end{array}$ \\
\hline $\begin{array}{l}\text { Caudate nucleus: } \\
\text { - Normal }\end{array}$ & $35(100 \%)$ & $35(100 \%)$ & \\
\hline $\begin{array}{l}\text { Putamen: } \\
\text { - Normal }\end{array}$ & $35(100 \%)$ & $35(100 \%)$ & \\
\hline $\begin{array}{l}\text { Globus pallidus: } \\
\text { - Normal } \\
\text { - Bilateral symmetrical } \\
\text { hyperintensity } \\
\text { - Hypointensity of left } \\
\text { glopuspallidus }\end{array}$ & $\begin{array}{ll}32 & (91.43 \%) \\
2 & (5.71 \%) \\
1 & (2.86 \%)\end{array}$ & $\begin{array}{ll}32 & (91.43 \%) \\
3 & (8.57 \%) \\
0 & (0.00 \%)\end{array}$ & 1.000 \\
\hline $\begin{array}{l}\text { Lentiform nucleus: } \\
\text { - Normal }\end{array}$ & $35(100 \%)$ & $35(100 \%)$ & \\
\hline $\begin{array}{l}\text { Anterior midbrain: } \\
\text { - Normal } \\
\text { - Hyperintense }\end{array}$ & $\begin{array}{l}35(100 \%) \\
0 \quad(0.00 \%)\end{array}$ & $\begin{array}{l}33(94.29 \%) \\
2 \quad(5.71 \%)\end{array}$ & 0.473 \\
\hline $\begin{array}{l}\text { Thalami: } \\
\text { - Normal } \\
\text { - Bilateral symmetrical } \\
\text { hyperintensity }\end{array}$ & $\begin{array}{ll}34 & (97.14 \%) \\
1 & (2.86 \%)\end{array}$ & $\begin{array}{l}35(100 \%) \\
0 \quad(0.00 \%)\end{array}$ & 1.000 \\
\hline $\begin{array}{l}\text { Periaqueductal region: } \\
\text { - Normal }\end{array}$ & $35(100 \%)$ & $35(100 \%)$ & \\
\hline $\begin{array}{l}\text { Posterior high parietal } \\
\text { region: } \\
\text { - Normal }\end{array}$ & $35(100 \%)$ & $35(100 \%)$ & \\
\hline $\begin{array}{l}\text { Ventricular system: } \\
\text { - Normal } \\
\text { - Prominent } \\
\text { - Hydrocephalus }\end{array}$ & $\begin{array}{ll}33 & (94.29 \%) \\
1 & (2.86 \%) \\
1 & (2.86 \%)\end{array}$ & $\begin{array}{ll}35 & (100 \%) \\
0 & (0.00 \%) \\
0 & (0.00 \%)\end{array}$ & 0.500 \\
\hline Total affected patients & $5(14.29 \%)$ & $3(8.57 \%)$ & 0.452 \\
\hline
\end{tabular}


Table (1): This table shows that there was no significant statistical difference between the two groups as regard $\mathrm{T} 1$ weighted images findings $(p>0.05)$.

Table (2): Comparison between WD group \& CLD group as regard $\mathrm{T} 2$ weighted images findings.

\begin{tabular}{llll}
\hline G2 Groups & $\begin{array}{c}\mathrm{WD} \\
\mathrm{n}=35 \mathrm{n}(\%)\end{array}$ & $\begin{array}{c}\mathrm{CLD} \\
\mathrm{n}=35 \mathrm{n}(\%)\end{array}$ & $\begin{array}{c}p- \\
\text { value }\end{array}$ \\
\hline $\begin{array}{l}\text { Caudate nucleus: } \\
\text { - Normal }\end{array}$ & $27(77.14 \%)$ & $35(100 \%)$ & $0.009^{*}$ \\
$\begin{array}{l}\text { Bilateral symmetrical } \\
\text { hyperintensity }\end{array}$ & $8(22.86 \%)$ & $0(0.00 \%)$ &
\end{tabular}

Putamen:

$\begin{array}{llll}\text { - Normal } & 31(88.57 \%) & 35(100 \%) & 0.122\end{array}$

- Bilateral symmetrical $4(11.43 \%) \quad 0(0.00 \%)$

hyperintensity

Globus pallidus:

- Normal $33(94.29 \%) \quad 35(100 \%) \quad 0.500$

- Bilateral symmetrical $1(2.86 \%) \quad 0(0.00 \%)$

hyperintensity

- Hyperintensity of left $1(2.86 \%) \quad 0(0.00 \%)$

glopuspallidus

Lentiform nucleus:

$\begin{array}{llll}\text { - Normal } & 30(85.71 \%) & 35(100 \%) & 0.063\end{array}$

- Bilateral symmetrical $5(14.29 \%) \quad 0(0.00 \%)$

hyperintensity

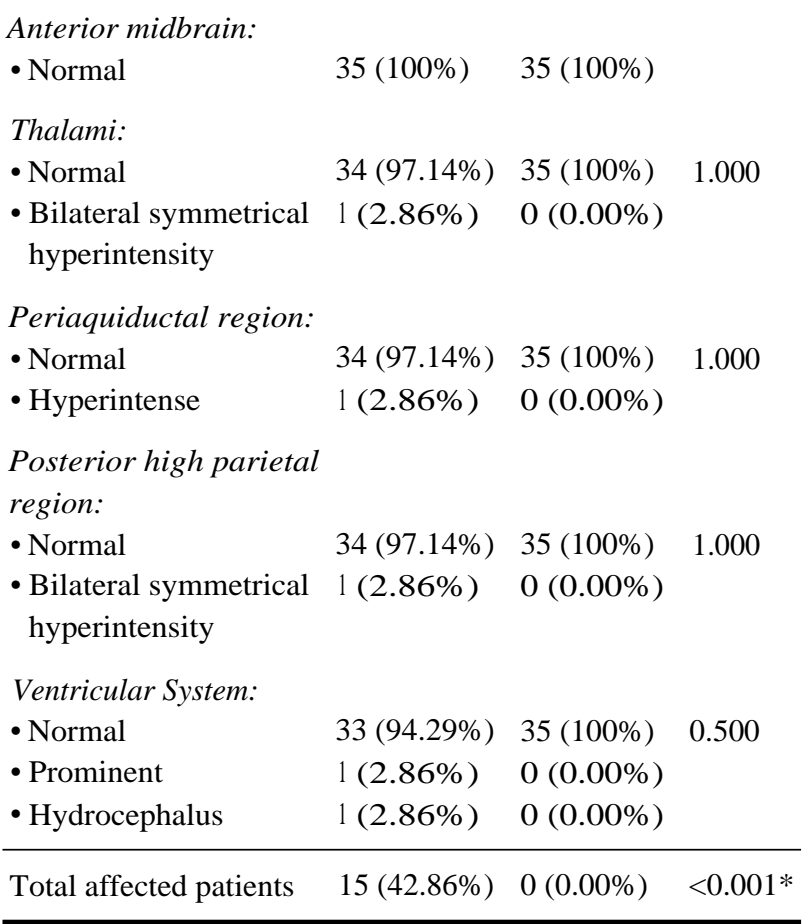

Table (2): This table shows that abnormalities in T2 weighted images were significantly higher in WD group than CLD group $(p<0.001)$.
Table (3): Comparison between WD group \& CLD group as regard FLAIR images findings.

\begin{tabular}{|c|c|c|c|}
\hline Groups & $\begin{array}{c}\text { WD } \\
\mathrm{n}=35 \mathrm{n}(\%)\end{array}$ & $\begin{array}{c}\text { CLD } \\
\mathrm{n}=35 \mathrm{n}(\%)\end{array}$ & $\begin{array}{c}p- \\
\text { value }\end{array}$ \\
\hline \multicolumn{4}{|l|}{ Caudate nucleus: } \\
\hline • Normal & $27(77.14 \%)$ & $35(100 \%)$ & $0.009 *$ \\
\hline $\begin{array}{l}\text { - Bilateral symmetrical } \\
\text { hyperintensity }\end{array}$ & $8(22.86 \%)$ & $0(0.00 \%)$ & \\
\hline \multicolumn{4}{|l|}{ Putamen: } \\
\hline • Normal & $31(88.57 \%)$ & $35(100 \%)$ & 0.122 \\
\hline $\begin{array}{l}\text { - Bilateral symmetrical } \\
\text { hyperintensity }\end{array}$ & $4(11.43 \%)$ & $0(0.00 \%)$ & \\
\hline \multicolumn{4}{|l|}{ Glopuspallidus: } \\
\hline • Normal & $34(97.14 \%)$ & $35(100 \%)$ & 1.000 \\
\hline $\begin{array}{l}\text { - Bilateral symmetrical } \\
\text { hyperintensity }\end{array}$ & $1(2.86 \%)$ & $0(0.00 \%)$ & \\
\hline \multicolumn{4}{|l|}{ Lentiform nucleus: } \\
\hline • Normal & $30(85.71 \%)$ & $35(100.0 \%)$ & 0.063 \\
\hline $\begin{array}{l}\text { - Bilateral symmetrical } \\
\text { hyperintensity }\end{array}$ & $5(14.29 \%)$ & $0(0.00 \%)$ & \\
\hline \multicolumn{4}{|l|}{ Anterior midbrain: } \\
\hline • Normal & $35(100 \%)$ & $35(100 \%)$ & \\
\hline \multicolumn{4}{|l|}{ Thalami: } \\
\hline • Normal & $34(97.14 \%)$ & $35(100 \%)$ & 1.000 \\
\hline $\begin{array}{l}\text { - Bilateral symmetrical } \\
\text { hyperintensity }\end{array}$ & $1(2.86 \%)$ & $0(0.00 \%)$ & \\
\hline \multicolumn{4}{|c|}{ Periaquiductal region: } \\
\hline - Normal & $34(97.14 \%)$ & $35(100 \%)$ & 1.000 \\
\hline - Hyperintense & $1(2.86 \%)$ & $0(0.00 \%)$ & \\
\hline \multicolumn{4}{|l|}{$\begin{array}{l}\text { Posterior high parietal } \\
\text { region: }\end{array}$} \\
\hline • Normal & $35(100 \%)$ & $35(100 \%)$ & \\
\hline \multicolumn{4}{|l|}{ Ventricular system: } \\
\hline • Normal & $33(94.29 \%)$ & $35(100 \%)$ & \\
\hline • Prominent & $1(2.86 \%)$ & $0(0.00 \%)$ & \\
\hline - Hydrocephalus & $1(2.86 \%)$ & $0(0.00 \%)$ & 0.500 \\
\hline Total affected patients & $14(40 \%)$ & $0(0.00 \%)$ & $<0.001 *$ \\
\hline
\end{tabular}

Table (3): This table shows that abnormalities in FLAIR images were significantly higher in WD group than CLD group $(p<0.001)$.

Table (4): Relation of MRI abnormality to the presence of neurological signs in WD subgroups.

\begin{tabular}{lcc}
\hline $\begin{array}{l}\text { Neurological } \\
\text { signs }\end{array}$ & $\begin{array}{c}\text { Abnormal MRI group } \\
\mathrm{n}=15 \\
\mathrm{n} \%\end{array}$ & $\begin{array}{c}\text { Normal MRI group } \\
\mathrm{n}=20 \\
\mathrm{n} \%\end{array}$ \\
\hline Positive & $6(40 \%)$ & $0(0.00 \%)$ \\
Negative & $9(60 \%)$ & $20(100 \%)$ \\
\hline
\end{tabular}

Table (4): This table shows that $60 \%$ of WD patients with abnormal MRI were neurologically free at time of MRI. 


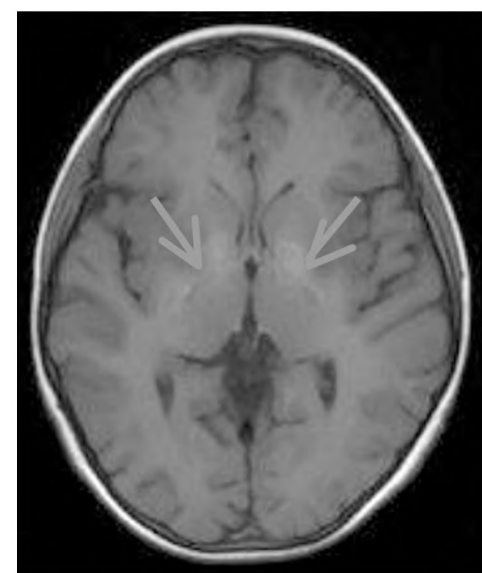

Fig. (1A): T1.

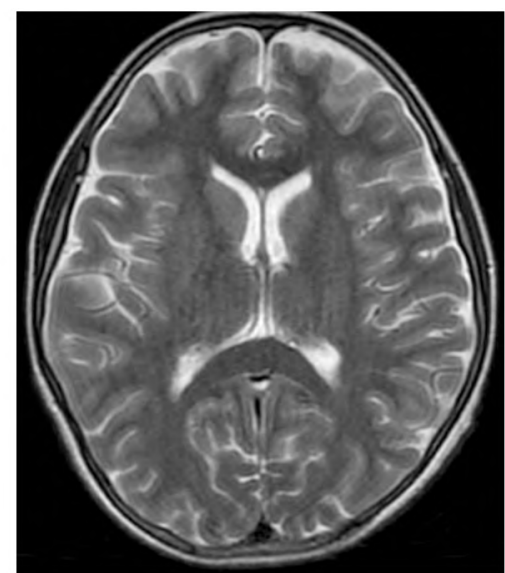

Fig. (1B): T2.

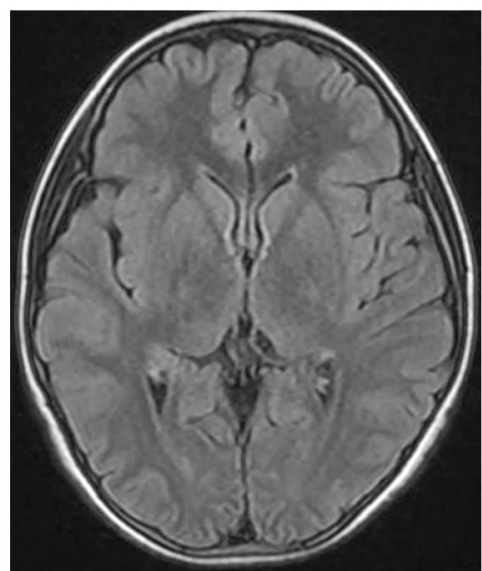

Fig. (1C): FLAIR.

Fig. (1): (A,B,C): Show axial views of brain MRI (without contrast) of a 14 years old male with AIH with bilateral symmetrical hyperintensity signals of glopuspallidus in T1 weighted images (1A) (arrows) and normal T2 weighted \& FLAIR images $(\mathrm{B}, \mathrm{C})$.

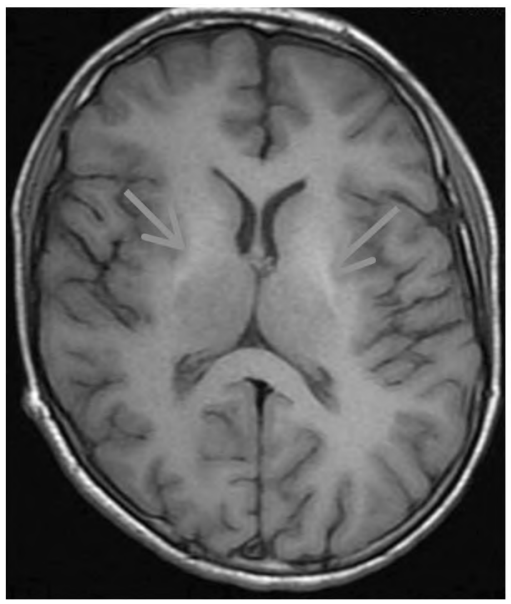

Fig. (2A): T1.

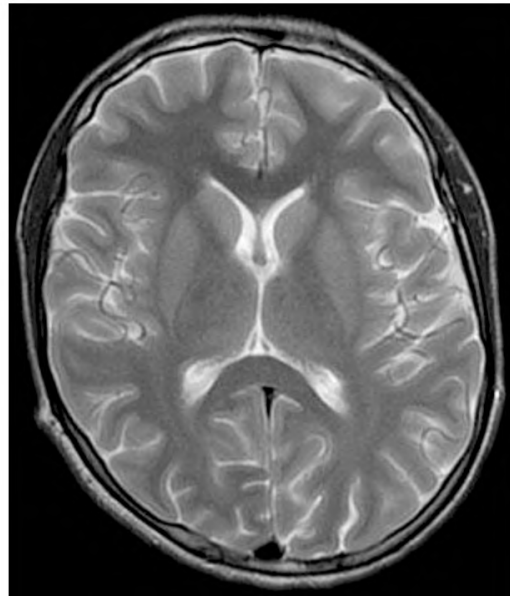

Fig. (2B): T2.

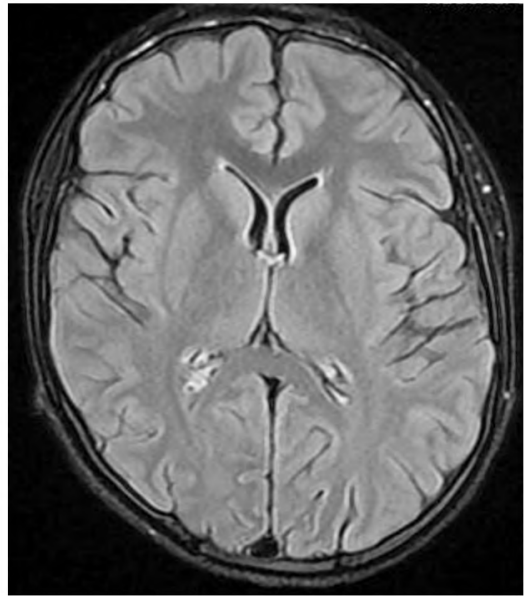

Fig. (2C): FLAIR.

Fig. (2): (A,B,C): Show axial views of brain MRI (without contrast) of a 12 years old male with WD with T1 bilateral symmetrical hyperintensity signals of glopuspallidus (A) (arrows) \& normal T2 weighted and FLAIR images (B,C).

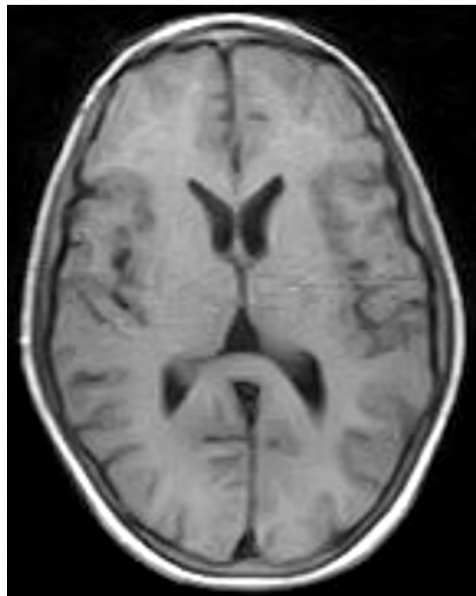

Fig. (3A): T1.

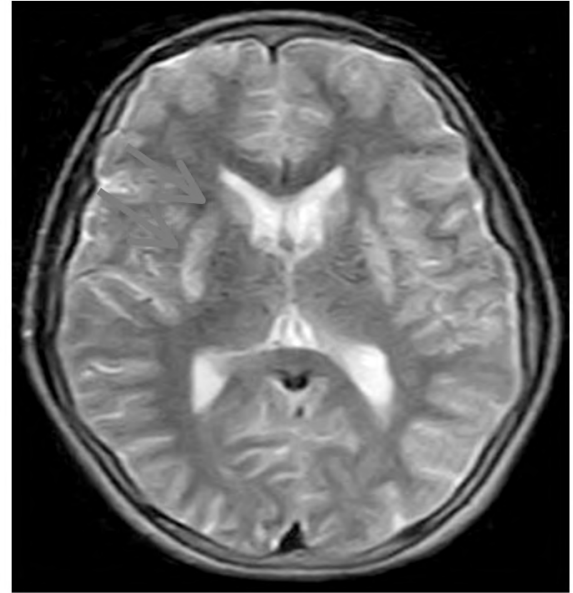

Fig. (3B): T2.

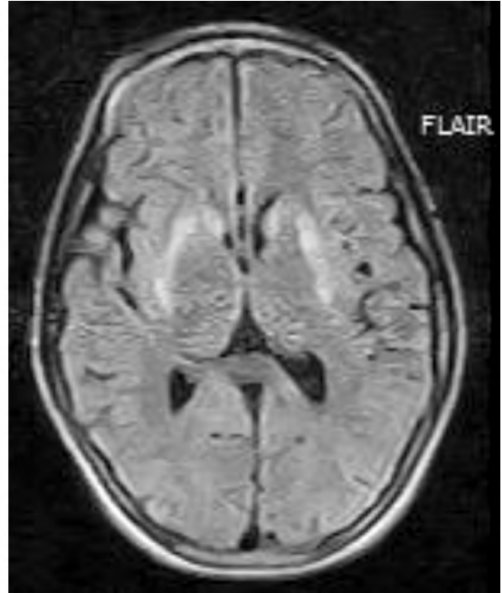

Fig. (3C): FLAIR.

Fig. (3): (A,B,C): Show axial views of brain MRI (without contrast) of a 13 years old male with WD with bilateral symmetrical hyperintensity signals of caudate nuclei and lentiform nuclei in T2 weighted \& FLAIR images (B,C) (arrows) and normal T1 weighted image (A). 
Table (5): Comparison between normal and abnormal MRI WD subgroups.

\begin{tabular}{|c|c|c|c|}
\hline & $\begin{array}{l}\text { Normal MRI } \\
\text { group } n=20 \\
n(\%)\end{array}$ & $\begin{array}{c}\text { Abnormal MRI } \\
\text { group } \mathrm{n}=15 \\
\mathrm{n}(\%)\end{array}$ & $\begin{array}{c}p- \\
\text { value }\end{array}$ \\
\hline \multicolumn{4}{|l|}{ Type of presentation: } \\
\hline • Presymptomatic & $8(40 \%)$ & $0(0 \%)$ & \multirow[t]{4}{*}{$0.020 *$} \\
\hline $\begin{array}{l}\text { - Picture of acute } \\
\text { hepatitis }\end{array}$ & $5(25 \%)$ & $3 \quad(20 \%)$ & \\
\hline - Picture of CLD & $7(35 \%)$ & $11(73.33 \%)$ & \\
\hline $\begin{array}{l}\text { - Neurologic } \\
\text { presentation }\end{array}$ & $0(0 \%)$ & $1 \quad(6.67 \%)$ & \\
\hline \multicolumn{4}{|l|}{$\begin{array}{l}\text { Duration of illness } \\
\text { (months): }\end{array}$} \\
\hline - Min-max & $0.5-108.0$ & $1.0-84.0$ & \multirow[t]{2}{*}{0.184} \\
\hline - Mean \pm SD & $39.5 \pm 40.3$ & $24.2 \pm 26.1$ & \\
\hline \multicolumn{4}{|l|}{$\begin{array}{l}24 \text { hours urinary } \\
\text { Copper at time of } \\
\text { MRI }(\text { g hours }) \text {. }\end{array}$} \\
\hline - Min-max & $27.00-1012$ & $51.00-760$ & \multirow[t]{2}{*}{0.986} \\
\hline - Mean \pm SD & $232.05 \pm 268.60$ & $230.54 \pm 208.15$ & \\
\hline \multicolumn{4}{|l|}{ Child Pugh score: } \\
\hline - Class A & $16(80 \%)$ & $9(60 \%)$ & \multirow[t]{3}{*}{0.061} \\
\hline - Class B & $0 \quad(0.00 \%)$ & $4(26.67 \%)$ & \\
\hline - Class C & $4(20 \%)$ & $2(13.33 \%)$ & \\
\hline
\end{tabular}

Table (5): There was significant statistical difference between the two groups as regard type of presentation $(p<0.05)$.

\section{Discussion}

Wilson's disease is an inherited disorder of hepatic copper metabolism with considerable variation in clinical presentations, the most common ones being liver disease and neuropsychiatric disturbances [9].

In this study, $51.4 \%$ presented by picture of CLD, $22.8 \%$ presented by acute hepatitis and $3 \%$ with neurologic presentation, while $22.8 \%$ were diagnosed presymptomatic during family screening of siblings of patients. In hand with our results, Gheorghe et al., 2004 reported that $52.8 \%$ presented by CLD picture and $25.4 \%$ were presymptomatic. This maximizes the importance of family screening, as it is a main step for the diagnosis of WD to allow treatment of asymptomatic patients in order to avoid hepatic and neurological complications [11]. In agreement with our results about neurologic symptoms in WD group, Machado et al., 2006 reported that dysarthria and abnormal gait were the most common neurological symptoms. While Noureen and Rana, 2011 reported that dystonia and dysarthria were the most common neurological symptoms. We reported that MRI abnormality was significantly statistically higher in WD group than CLD group ( $p=0.003)$. We reported that there was no significant statistical difference between CLD group and WD group as regard T 1 weighted images finding ( $p>0.05)$. This is due to that WD as a CLD can produce brain abnormalities similar to that produced by other CLDs. In CLD, the most characteristic findings of T1-weighted images are a bilateral and symmetric high signal in the region of basal ganglia mostly globuspallidus. This is attributed to manganese accumulation secondary to failed hepatobiliary clearance and portosystemic shunting [14]. Indeed, pallidal manganese concentrations are elevated in cirrhotic patients dying with hepatic coma. Other brain areas can also accumulate manganese, albeit to a lesser extent. Elevated CSF manganese levels have been documented in patients with liver failure, consistent with more widespread manganese accumulation [15]. Manganese is a paramagnetic metal that shortens the T1 relaxation time sufficient to produce T1 hyperintensity. In contrast, copper typically results in increased T2 signal abnormalities only, because copper does not have the paramagnetic properties to generate T1 hyperintensity [16]. Among WD group, we reported 15 patients $(42.8 \%)$ hadabnormal MRI. While Li et al., 2019 detected abnormal MRI in only $4.4 \%$ of WD patients. This may be due to younger age at diagnosis (5.9 years) and higher percent of presymptomatic patients $(86 \%)$ in their study. We reported that globuspallidus was the most common affected site in $\mathrm{T} 1$ weighted images in WD group. Our result is in agreement with Bayram et al., 2016 who reported that globuspallidus is the most affected in T1 weighted images in WD patients. In this study, T2 bilateral basal ganglionic lesions were the commonest changes. Consistent with our result, Ranjan et al., 2015 reported that T2 bilateral basal ganglia lesions were the commonest and suggestive of WD. Among basal ganglia nuclei, caudate nucleus was the most affected in T2 weighted images followed by lentiform nucleus then putamen. This disagree with Salari et al., 2018 who reported that putamen was the most affected site followed by pons followed by midbrain in $\mathrm{T} 2$ weighted images. Lesions in FLAIR images were similar to T2 weighted images except in one patient. Hyperintense signal of caudate nucleus was the most common followed by lentiform nucleus then putamen. This result is in agreement with that reported by Ranjan et al., 2015. We reported that MRI brain lesions were bilateral and symmetrical in all patients except in one patient who had signal abnormality affecting only left globuspallidus, this in agreement with Ranjan et al., 2015 and Zhong et al., 2019 who reported that brain lesions in MRI of WD patients were bilateral and symmetric. In our study, 
bilateral symmetrical hyperintensity of caudate nucleus in T2 weighted \& FLAIR images was the commonest lesion in patients who had dysarthria and abnormal gait. In hand with our result, Sinha et al., 2006 reported that caudate lesions have a significant association with dysarthria. In our study, brain MRI of the patient who had dystonia showed bilateral symmetrical hyperintensity of caudate nucleus and putamen in T2 \& FLAIR images. Consistent with our result, Svetel et al., 2001 reported correlation of dystonia with putamen lesion. It is still not clear when brain involvement in WD becomes symptomatic. We reported that $60 \%$ of WD patients, who had abnormal MRI, were neurologically free at time of MRI. In hand with our result, Güngör et al., 2018 reported that $42.1 \%$ had abnormal MRI without any clinical sign. There was no significant statistical difference between the two WD subgroups as regard liver function $(p<0.05)$ except AST/ALT ratio also there was no significant statistical difference between the two WD subgroups as regard 24 hours urinary copper at time of MRI. In accordance to our results, Sinha et al., 2006 reported that MRI changes did not correlate with duration of illness. But these results disagree with Zhong et al., 2019 who reported that disease duration in MRI-abnormal patients was significant longer than that in patients who were MRI normal. We reported that all presymptomatic patients had normal MRI. In hand with our result Sinha et al., 2006 reported that all presymptomatic patients had normal MRI.

\section{Conclusions:}

All CLD patients had normal T2 weighted and FLAIR images. Bilateral symmetrical hyperintense signals in T2 weighted and FLAIR images mainly involving basal ganglia are specific for WD and represent CNS involvement of WD. Caudate nucleus was the most common affected site in T2 weighted and FLAIR images followed by lentiform nucleus. Bilateral symmetrical hyperintensity of caudate nucleus in T2 weighted and FLAIR images was the most common lesion in WD patients who had dysarthria and abnormal gait. Abnormal MRI may be a bad prognostic factor as $20 \%$ from abnormal MRI WD subgroup deteriorated rapidly and were candidates for LT.

\section{References}

1- LOUDIANOS G., CHIAPPE, F. and LEPORI M.B.: Wilson Disease in the Mediterranean Region: Clinical and Translational Perspectives on WILSON DISEASE. Elsevier, pp. 311-8, 2019.

2- KERKAR N. and ROBERTS E.A.: Wilson Disease in Infancy through Adolescence: Clinical and Translational
Perspectives on WILSON DISEASE. Elsevier, pp. 17993, 2019.

3- MAK C.M.: Biochemical Diagnosis of Wilson Disease: Clinical and Translational Perspectives on WILSON DISEASE. Elsevier, pp. 237-48, 2019

4- DUSEK P., LITWIN T. and CZLONKOWSKA A.: Neurologic impairment in Wilson disease. Annals of translational medicine 7, 2019.

5- LITWIN T., DZIE_YC K. and CZLONKOWSKA A.: Wilson disease-treatment perspectives. Annals of translational medicine, 7: 1-24, 2019.

6- AGGARWAL A. and BHATT M.: Neurological Wilson Disease: Clinical and Translational Perspectives on WILSON DISEASE. Elsevier, pp. 195-214, 2019.

7- LORINCZ M.T.: Neurologic Wilson's disease. Annals of the New York Academy of Sciences 1184, 173-87, 2010.

8- GHAFFAR T.Y.A., ELSAYED S.M., ELNAGHY S., SHADEED A., ELSOBKY E.S. and SCHMIDT H.: Phenotypic and genetic characterization of a cohort of pediatric Wilson disease patients. BMC Pediatr., 11: 11-56, 2011.

9- FERENCI P., STREMMEL W., CZLONKOWSKA A., SZALAY F., VIVEIROS A., STÄTTERMAYER A.F., BRUHA R., HOUWEN R., POP T.L. and STAUBER R.: Age and Sex but Not ATP7B Genotype Effectively Influence the Clinical Phenotype of Wilson Disease. Hepatology, 69: 1464-76, 2019.

10- GHEORGHE L., POPESCU I., IACOB S., GHEORGHE C., VAIDAN R., CONSTANTINESCU A., IACOB R., BECHEANU G., ANGELESCU C. and DICULESCU M.: Wilson's Disease: A challenge of diagnosis. The 5year experience of a tertiary centre. Rom. J. Gastroenterol., 13: 179-85, 2004.

11- TROCELLO J.M., EL BALKHI S., WOIMANT F., GIRARDOT-TINANT N., CHAPPUIS P., LLOYD C. and POUPON J.: Relative exchangeable copper: A promising tool for family screening in Wilson disease. Movement Disorders, 29: 558-62, 2014.

12- MACHADO A., FEN CHIEN H., MITIKO DEGUTI M. CANÇADO E., SOARESAZEVEDO R., SCAFF M. and REIS BARBOSA E.: Neurological manifestations in Wilson's disease: Report of 119 cases. Movement disorders: Official Journal of the Movement Disorder Society, 21: 2192-6, 2006

13- NOUREEN N. and RANA M.T.: Neurological Wilson disease in children: A three years' experience from Multan. JPMA-Journal of the Pakistan Medical Association, 61: 743, 2011.

14- CHAVARRIA L. and CORDOBA J.: Magnetic resonance of the brain in chronic and acute liver failure. Metabolic Brain Disease, 29: 937-44, 2014.

15- KLOS K.J., AHLSKOG J.E., JOSEPHS K.A., FEALEY R.D., COWL C.T. and KUMAR N.: Neurologic spectrum of chronic liver failure and basal ganglia $\mathrm{T} 1$ hyperintensity on magnetic resonance imaging: Probable manganese neurotoxicity. Archives of Neurology, 62: 1385-90, 2005.

16- KLOS K., AHLSKOG J., KUMAR N., CAMBERN S., BUTZ J., BURRITT M., FEALEY R., COWL C., PARISI J.E. and JOSEPHS K.A.: Brain metal concentrations in chronic liver failure patients with pallidal T1 MRI hyperintensity. Neurology, 67: 1984-9, 2006. 
17- LI X., LU Z., LIN Y., LU X., XU Y., CHENG J., SHAO Y., SU X., LIU Z. and SHENG H.: Clinical features and mutational analysis in 114 young children with Wilson disease from South China. American Journal of Medical Genetics Part A, 179: 1451-8, 2019.

18- BAYRAM A.K., GÜMÜS H., ARSLAN D., ÖZCORA G.K., KUMANDAS S., KARACABEY N., CANPOLAT M. and PER H.: Neurological features and management of Wilson disease in children: An evaluation of 12 cases. Turkish Archives of Pediatrics/TürkPediatriAr sivi, 51, 15, 2016.

19- RANJAN A., KALITA J., KUMAR S., BHOI S. and MISRA U.: A study of MRI changes in Wilson disease and its correlation with clinical features and outcome. Clinical Neurology and Neurosurgery, 138: 31-6, 2015.

20- SALARI M., FAYYAZI E. and MIRMOSAYYEB O.: Magnetic resonance imaging findings in diagnosis and prognosis of Wilson disease. Journal of research in medical sciences: The official journal of Isfahan University of Medical Sciences, 23: 1-13, 2018.

21- ZHONG W., HUANG Z. and TANG X.: A study of brain MRI characteristics and clinical features in 76 cases of Wilson's disease. Journal of Clinical Neuroscience, 59: 167-74, 2019

22- SINHA S., TALY A., RAVISHANKAR S., PRASHANTH L., VENUGOPAL K., ARUNODAYA G., VASUDEV M. and SWAMY H.: Wilson's disease: Cranial MRI observations and clinical correlation. Neuroradiology, 48: 613$21,2006$.

23- SVETEL M., KOZIC'D., STEFANOVA E., SEMNIC R., DRAGASEVIC N. and KOSTIC V.S.: Dystonia in Wilson's disease. Movement Disorders, 16: 719-23, 2001.

24- GÜNGÖR S., SELIMOGLU M.A., VAROL Fi. and GÜNGÖR S.: Pediatric Wilson's disease: Findings in different presentations. A cross-sectional study. Sao Paulo Medical Journal, 136: 304-9, 2018.

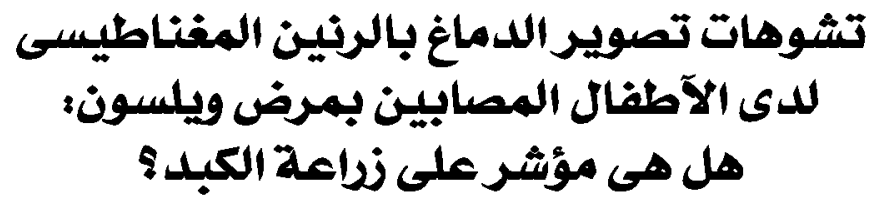

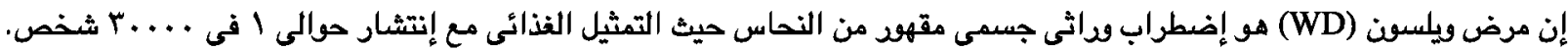

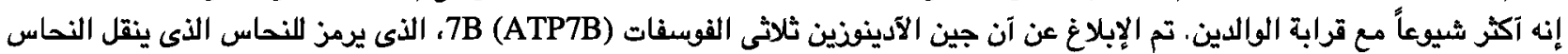

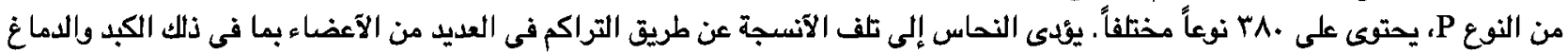

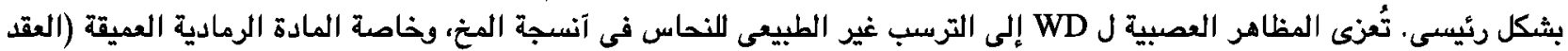

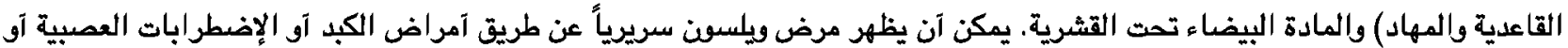

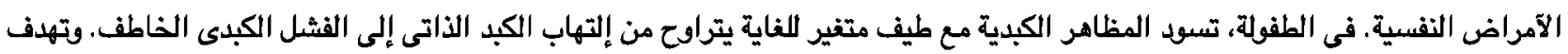

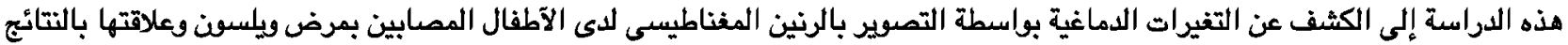

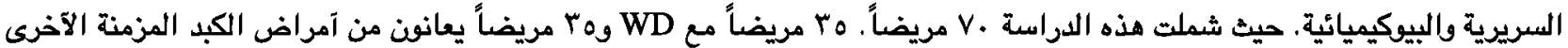

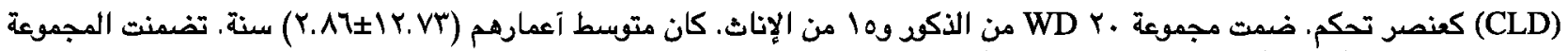

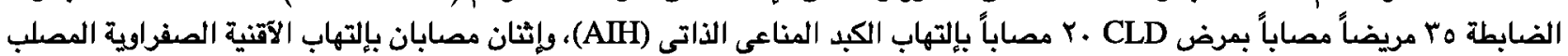

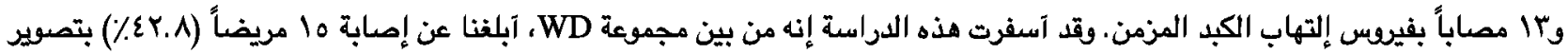

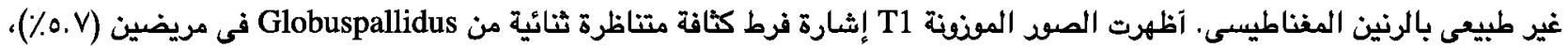

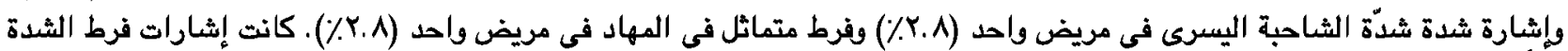

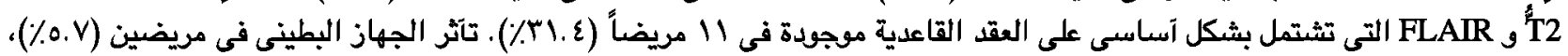

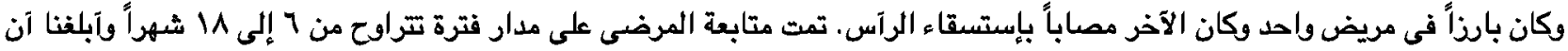

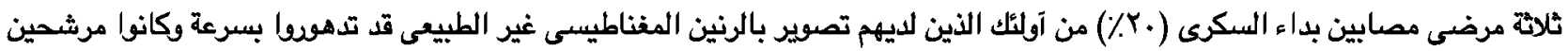

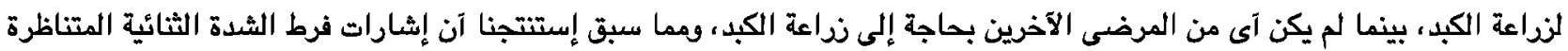

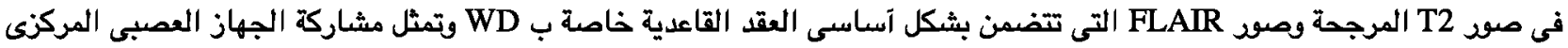

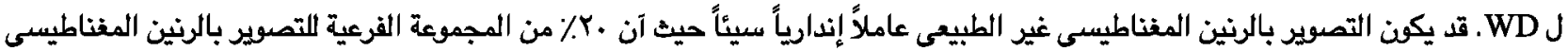

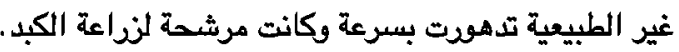

